\title{
BMJ Open Understanding the beliefs and attitudes towards mental health problems held by Muslim communities and acceptability of cognitive behavioural therapy as a treatment: systematic review and thematic synthesis protocol
}

To cite: Alharbi H, Farrand P, Laidlaw $\mathrm{K}$. Understanding the beliefs and attitudes towards mental health problems held by Muslim communities and acceptability of cognitive behavioural therapy as a treatment: systematic review and thematic synthesis protocol. BMJ Open 2021;11:e044865. doi:10.1136/ bmjopen-2020-044865

- Prepublication history and additional supplemental material for this paper are available online. To view these files, please visit the journal online. To view these files, please visit the journal online (http://dx.doi. org/10.1136/bmjopen-2020044865).

Received 22 September 2020 Accepted 28 May 2021

Check for updates

(C) Author(s) (or their employer(s)) 2021. Re-use permitted under CC BY-NC. No commercial re-use. See rights and permissions. Published by BMJ.

Clinical Education Development and Research (CEDAR)

Psychology, College of Life and Environmental Sciences, University of Exeter, Exeter, UK

Correspondence to

Ms Hind Alharbi;

ha431@exeter.ac.uk

\section{ABSTRACT}

Introduction Many barriers prevent Muslims' accessing mental health services, the aim of this systematic review is to gain an understanding regarding these barriers and consider how they vary across different Muslim communities resident in different countries.

Methods and analysis Systematic review of PubMed/ MEDLINE, CINAHL, PsycINF0, Ovid MEDLINE, Embase and Index Islamicus databases for studies published in English in addition to the Saudi Digital Library for studies published in Arabic. The review will include quantitative, qualitative and mixed methods studies published in peer-review journals since 1980. Methodological quality and risk of bias of included papers will be critically appraised independently according to the Mixed Methods Appraisal Tool. Thematic synthesis will be used to extract outcome and analyse data from studies included in the review. Ethics and dissemination There are considered to be no ethical issues. Findings will be disseminated in both English and Arabic to clinicians and researchers via journal publication and conference presentation(s). Trial registration number CRD42020192854.

\section{INTRODUCTION}

Islam is the dominant religion in 56 countries around the globe and has more than 1.9 billion followers. ${ }^{1}$ The majority of Muslims reside in the Islamic world that primarily covers the Middle East, Africa and Asia. However, Muslims are also resident in many non-Muslim countries as a minority group having immigrated for economic, political or social reasons. ${ }^{2}$ Muslims may be affected and differ by their residential and cultures norms. ${ }^{3}$ For example, although the Qur'an clearly states that certain behaviours such as drinking alcohol and eating pork are forbidden, it has been reported that $25 \%$ of Korean Muslims
Strengths and limitations of this study

- First protocol for a systematic review and thematic synthesis examining barriers that prevent Muslims accessing mental health services.

- The review is inclusive regarding barriers held by different Muslim communities that live in different countries to facilitate comparisons.

- Studies restricted to those published in English or Arabic since 1980.

- Due to limited resources, in this review focus has only been on cognitive behavioural therapy.

drink alcohol with $16 \%$ eating pork. ${ }^{4}$ Participants in this study reported that engaging in such behaviours arose as a response to their cultural upbringing, indicating that differences exist between Muslim communities residing in different countries.

Differences have also been reported in areas such as engaging with, and access to, mental health services. When accessing mental health services, Muslims experience a lower recovery rate $(40.3 \%)$, compared with Christians $(54.5 \%)$ and Jews $(49.5 \%)^{56}$ Worse recovery rates for Muslims potentially reflecting a strong relationship between the Islamic religion with their response to all external events varying with the degree of religiosity. ${ }^{7}$ Furthermore, compared with other religious groups, Muslims have also been reported to experience a range of additional barriers that prevent them from accessing mental health services. Within the UK, Muslims have been identified to be at a significant disadvantage when using mental health services ${ }^{8}$ with access to psychological services remaining low in the UK. ${ }^{5}$ 
While many Muslims believe that mental health difficulties represent medical problems, some believe the aetiology of mental health difficulties is associated with beliefs in Evil Eye, possession, black magic ${ }^{9}$ or as a punishment from Allah for sinful acts. ${ }^{10-12}$ Additionally, limited access to mental health services for Muslims has also been reported, ${ }^{13}$ resulting in treatment sought from religious healers rather than mental health services. ${ }^{13}{ }^{14}$ While some barriers to access are known, little is known about how these differ across Muslim communities resident in different countries.

However, a systematic review conducted on Muslims and non-Muslims in Middle Eastern Arab countries has identified a range of barriers engaging with mental health interventions. ${ }^{15}$ Barriers included the acceptance of interference in the cultural context (eg, beliefs and values and the stigma of mental illnesses), community and system factors (eg, access to services) and clinical participation processes (eg, the expectations of the client). ${ }^{15}$ These barriers are similar to those reported in Western societies examining access to effective treatment for anxiety and depression. These included factors related to culture, the provider such as lack of knowledge of mental health problems and of a systemic nature such as the limited availability of specialty mental health providers. ${ }^{16}$ Somewhat surprisingly, however, individual barriers ${ }^{16}$ relating to an understanding of mental health and treatment were not reported.

This systematic review seeks to gain a fuller understanding concerning barriers that prevent Muslims in different countries from accessing mental health service with a secondary focus examining barriers that prevent Muslims from accessing cognitive behavioural therapy (CBT) as treatment. Examining barriers effecting Muslim communities resident in different countries will improve understanding regarding the extent to which any differences permit conclusions to be generalised across community.

\section{AIMS AND OBJECTIVES \\ Aim}

Understand barriers that prevent adult Muslims from accessing mental health services with comparisons undertaken between Muslim communities resident in different countries.

\section{Objectives}

Gain an understanding of barriers that prevent Muslim communities resident in different countries accessing mental health services.

Appreciate beliefs and attitudes regarding causes and treatment of mental health difficulties.

Evaluate the extent to which beliefs held towards mental health and treatment vary between Muslim communities resident in different countries.

Appreciate the extent that CBT may address barriers for adult Muslims.

\section{METHOD}

This systematic review protocol adheres to the Preferred Reporting Items for Systematic Reviews and Meta-Analyses (see online supplemental appendix 1).

\section{Eligibility criteria}

Empirical studies published in peer-review journals and meeting review-specific eligibility criteria informed by the SPIDER search tool for use in systematic reviews of qualitative and mixed-method research. ${ }^{17}$ All studies will be published since 1980 in the English and Arabic language. Grey literature will be excluded.

\section{Study population}

The study population includes working age male and female adult Muslims that have either not received psychological therapies for the treatment of mental health difficulties or only received treatment with CBT. Working age varies between countries and as such will differ as an inclusion criterion. On occasions participant religion may not be specified in the description of the participants. In such cases, studies conducted in countries where the population is above 90\% Muslim (eg, Afghanistan, Iran, Libya, Saudi Arabia, Somalia, Turkey, Pakistan) will be included. Studies that focus on healthcare professionals, family or carers views will be excluded.

\section{Interventions}

Studies focusing on general barriers to accessing mental health services will not be limited to any specific psychological intervention. However, studies focused on barriers to accessing a specific psychological therapy will be restricted to $\mathrm{CBT} .^{18}$

\section{Comparators}

Regardless of any comparator condition used in quantitative studies, all studies meeting inclusion criteria will be included.

\section{Study designs}

Qualitative, quantitative, questionnaire-based and mixed methods research designs will be included.

\section{Outcomes}

Understand barriers that prevent Muslims from accessing mental health services and identification of barriers accessing CBT for mental health difficulties.

\section{Language}

Studies in the English or Arabic language.

\section{Patient and public involvement}

No patients involved.

\section{Information sources}

In the English language, the search will be based on the following research databases: PubMed/MEDLINE, CINAHL, PsycINFO, Ovid MEDLINE, Embase and the Index Islamicus religious database. The Saudi Digital 
Library (SDL) electronic database will be searched for publications in Arabic.

\section{Search strategy}

Truncation\# or Wild Cards* will be used following appropriate search terms to support searches for variations on a word formed through different suffixes. For example, Depressi* to include depression or depressive disorder or depressive symptoms or major depressive disorder. Or \# if the word has a different spelling such as behaviour\#. Where available, search terms will be adjusted for use with specific bibliographic databases filters. Truncation or Wild Cards are not used within the SDL. Reference lists will be hand searched for all included studies to identify further studies (see online supplemental appendices 2 and 3). HA reviewed the research strategy with the University of Exeter Librarian competent in this area.

\section{Study selection}

Prior to screening, a calibration exercise will be undertaken between HA and PF. All titles and abstracts yielded by the search against inclusion/exclusion criteria will be screened by HA. Full text of articles included from the title abstract screen will be independently reviewed by HA and $\mathrm{PF}$ with discrepancies regarding inclusion resolved through discussion. Where consensus is not reached, differences will be resolved by wider discussion with $\mathrm{KL}$ for final decision-making.

\section{Data extraction}

Descriptive data regarding background characteristicspopulation, year of publication, country of study, study aim, study design, population, type of mental health difficulties if experienced-will be extracted from each study included in the review. Consistent with the aim of qualitative synthesis to extend beyond primary studies, additional data extracted will focus on the analysis and interpretations of the study authors towards themes, subthemes, beliefs, models, attitudes and other relevant information associated with the study objectives. Data extraction forms will be developed and piloted a priori. For studies published in English, data extraction will be carried out by HA with a random sample checked by PF. Data extraction for studies published in the Arabic language will only be undertaken by HA.

\section{Risk of bias of individual studies}

Methodological quality and risk of bias of included papers will be critically appraised independently by HA and PF according to the Mixed Methods Appraisal Tool. ${ }^{19}$

\section{Data analysis and synthesis}

Thematic synthesis ${ }^{20}$ will be used to support interpretation of data obtained from qualitative, quantitative and mixed methods research beyond that undertaken by authors of included studies. Arising data will be organised to derive themes. Data will be entered into NVivo V.12 to support organisation and analysis. Three stages of thematic synthesis ${ }^{20}$ will be applied to data derived from all studies included in the systematic review.

\section{First stage: coding of text}

Selected studies will be coded line by line by HA, and results validated by PF. Any discrepancies in coding will be resolved through discussion or in further consultation with KL.

\section{Second stage: developing descriptive themes}

Reviewers will look for similarities and differences between codes in order to start grouping them into a hierarchical tree structure.$^{21}$ On the basis of similarities and differences between the data, HA will compile codes into descriptive topics. Data extracted from the first stage will be analysed to create potential themes and organised to form a hierarchical tree structure determined by themes. The aim of the hierarchical tree structure is to show themes with explanatory data and capture similarities within the data wherever possible. ${ }^{21}$ The results for this stage will be discussed with PF with discrepancies in coding resolved through discussion and consultation with KL.

\section{Third stage: generating analytical themes}

At this stage, analytical themes will be developed with analysis extending beyond the initial data reported in the previous stages. ${ }^{22}$ Analytical themes will be developed separately by HA and PF and discussed, with KL included at this stage where consensus cannot be reached.

Following thematic synthesis, results will be compared across studies to address review objectives and reach an understanding regarding the barriers to access and acceptability of CBT to address these barriers. Where they arise, comparisons will be made regarding these barriers with respect to the country of residence.

\section{DISCUSSION}

This systematic review will examine barriers that prevent adult Muslims from accessing mental health services. Within the Improving Access to Psychological Therapies (IAPT) programme, ${ }^{23}$ attempts to reduce barriers have predominantly focused on addressing provider and systemic barriers ${ }^{16}$ and restricted to services predominantly providing CBT. However, differences in barriers between Muslims resident in different countries will be explored to examine the potential that barriers experienced by the IAPT programme may vary by country of residence. Much less focus has been focused on examining individual barriers across cultures such as beliefs regarding mental health and attitudes towards psychological therapies. ${ }^{24}$ Comparison across Muslims resident in different countries will therefore help establish a degree of confidence in data synthesis to inform decision-making varying by country.

Contributors HA drafted the manuscript and led the design of the protocol and provided input across all areas. PF provided guidance during development of the 
protocol, provided advice across all areas and commented on all drafts. KL provided comments on full drafts.

Funding This study is financially supported by King Saud medical city (Saudi Arabia) through a PhD awarded to the University of Exeter.

Competing interests None declared.

Patient consent for publication Not required.

Provenance and peer review Not commissioned; externally peer reviewed.

Supplemental material This content has been supplied by the author(s). It has not been vetted by BMJ Publishing Group Limited (BMJ) and may not have been peer-reviewed. Any opinions or recommendations discussed are solely those of the author(s) and are not endorsed by BMJ. BMJ disclaims all liability and responsibility arising from any reliance placed on the content. Where the content includes any translated material, BMJ does not warrant the accuracy and reliability of the translations (including but not limited to local regulations, clinical guidelines, terminology, drug names and drug dosages), and is not responsible for any error and/or omissions arising from translation and adaptation or otherwise.

Open access This is an open access article distributed in accordance with the Creative Commons Attribution Non Commercial (CC BY-NC 4.0) license, which permits others to distribute, remix, adapt, build upon this work non-commercially, and license their derivative works on different terms, provided the original work is properly cited, appropriate credit is given, any changes made indicated, and the use is non-commercial. See: http://creativecommons.org/licenses/by-nc/4.0/.

ORCID iD

Hind Alharbi http://orcid.org/0000-0002-6721-7664

\section{REFERENCES}

1 World Population Review. Muslim population by country 2020, 2020. Available: https://worldpopulationreview.com/country-rankings/ muslim-majority-countries

2 Ali SR, Liu WM, Humedian M. Islam 101: understanding the religion and therapy implications. Prof Psychol 2004;35:635-42.

3 Yilmaz S. Cultural Muslims: background forces and factors influencing everyday religiosity of Muslim people. Journal of History Culture and Art Research 2014;3:1-19.

4 Kim HC. Din değisstirmenin entelektüel arka planı (Intellectual background of conversion). Istanbul: Kaynak Yay, 2003.

5 Health and Social Care Information Centre. Psychological therapies: annual report on the use of IAPT services, 2016. Available: http:// www.nationalarchives.gov.uk/doc/open-government-licence/version/ 3/

6 Moller NP, Ryans G, Rollings J. The 2018 UK NHS digital annual report on the improving access to psychological therapies programme: a brief commentary. BMC Psychiatry 2019;19:1:252.

7 Alrwaite A. Culture of the community and its relationship to the development of education (Arabic). Arabic Studies in Psychology 2010;4:643-85.
8 Meer S, Mir G, Serafin A. Addressing depression in Muslim communities. Leeds, UK: University of Leeds, 2012.

9 Al-Habeeb TA. A pilot study of faith healers' views on evil eye, jinn possession, and magic in the Kingdom of Saudi Arabia. J Family Community Med 2003;10:31.

10 Al-Adawi S, Dorvlo ASS, Al-Ismaily SS, et al. Perception of and attitude towards mental illness in Oman. Int $J$ Soc Psychiatry 2002;48:305-17.

11 Al-Issa I. Does the Muslim religion make a difference in psychopathology? In: Al-Issa Al-Junun I, ed. Mental illness in the Islamic world. Madison, CT: International Universities Press, 2000: 315-53.

12 Al-Subaie A, Alhamad A. Psychiatry in Saudi Arabia. In: Al-Junun A-I, ed. Mental illness in the Islamic world. Madison, CT: International Universities Press, 2000: 205-33.

13 Alhadi A, Algahtani H, Salem M. Cognitive behaviour therapy in middle east: 1. In: Naeem F, Kingdon D, eds. Cognitive behaviour therapy in non-Western cultures. Hauppauge, New York: Nova Science Publisher Inc, 2012: 93-101.

14 Algahtani H, Buraik Y, Ad-Dab'bagh Y. Psychotherapy in Saudi Arabia: its history and cultural context. J Contemp Psychother 2017;47:105-17.

15 Gearing RE, Schwalbe CS, MacKenzie MJ, et al. Adaptation and translation of mental health interventions in middle Eastern Arab countries: a systematic review of barriers to and strategies for effective treatment implementation. Int J Soc Psychiatry 2013;59:671-81.

16 Collins KA, Westra HA, Dozois DJA, et al. Gaps in accessing treatment for anxiety and depression: challenges for the delivery of care. Clin Psychol Rev 2004;24:583-616.

17 Cooke A, Smith D, Booth A. Beyond PICO: the spider tool for qualitative evidence synthesis. Qual Health Res 2012;22:1435-43.

18 Farrand P. Low-intensity cognitive behavioural therapy: revolution not evolution. In: Farrand P, ed. Low-Intensity CBT skills and interventions: a practitioners' manual. London: SAGE, 2020.

19 Pluye P, Hong QN. Combining the power of stories and the power of numbers: mixed methods research and mixed studies reviews. Annu Rev Public Health 2014;35:29-45.

20 Thomas J, Harden A. Methods for the thematic synthesis of qualitative research in systematic reviews. BMC Med Res Methodol 2008;8:45.

21 Thomas J, Sutcliffe K, Harden A. Children and healthy eating: a systematic review of barriers and facilitators. In database of Abstracts of reviews of effects (Dare). Quality-assessed reviews. York (UK: Centre for Reviews and Dissemination, 2003. https://www.ncbi.nlm. nih.gov/books/NBK70020/

22 Britten N, Campbell R, Pope C, et al. Using meta ethnography to synthesise qualitative research: a worked example. J Health Serv Res Policy 2002;7:209-15.

23 National Collaborating Centre for Mental Health. The improving access to psychological therapies manual, 2020. Available: https:// www.england.nhs.uk/wp-content/uploads/2020/05/iapt-manual-v4. pdf

24 Beck A, Naz S, Brooks M. Improving access to psychological therapies (IAPT). black, Asian and minority ethnic service user positive practice guide, 2019 